\title{
Factors affecting the obesity of the South Korean breast cancer patients as determined using propensity score matching.
}

\author{
Jeong Won Han', Hee Yeong Woo ${ }^{2 *}$ \\ ${ }^{1}$ Department of Nursing, Kyung Hee University, Republic of Korea \\ ${ }^{2}$ Department of Nursing, Sahmyook Health University, Republic of Korea
}

\begin{abstract}
The objectives of this study were to identify the factors affecting the obesity of breast cancer patients and to provide basic data for the development of an effective obesity management program for them using the propensity score matching method and data from the Korea National Health and Nutrition Examination Survey (KNHANES) with a bigger sample size and a higher level of representativeness. In this study, 231 breast cancer patients who had been diagnosed with breast cancer and had been treated for more than 3 months among the adult KNHANES participants (aged 19 and older) were selected. The results of this study showed that the degree of physical activity, the number of days of doing strength exercise, the food intake reduction level, the protein intake ratio, and the thermal effect of food affected the obesity of the breast cancer patients. Therefore, future studies are needed to examine the factors associated with the obesity management of breast cancer patients in various aspects, using a wide range of data, and to suggest political measures for managing the obesity of breast cancer patients.
\end{abstract}

Keywords: Breast cancer, Obesity, Propensity.

Accepted on March 12, 2019

\section{Introduction}

Breast cancer is the most common cancer among females in the world, and the second most common cancer among the women in South Korea, followed by thyroid cancer [1]. According to the data of Statistics Korea, 19,000 new breast cancer cases are reported every year, and the incident continues to increase particularly among females in the 40s and 50s [2]. As breast cancer is more commonly diagnosed in the early stage, its 5year survival rate continues to increase steadily, along with the increased breast cancer incident rate [3]. This can be attributed to the successful application of various treatments to breast cancer patients. Previous studies have shown, however, that overweight patients with a high body mass index (BMI) have a relatively lower survival rate despite the development and application of medical technologies for cancer treatment [4]. Therefore, weight control is emphasized for breast cancer patients. This is so particularly because other than the ovaries, the adipose tissue can also produce estrogen and can thus cause estrogen stimulation. Moreover, obesity rapidly increases the estrogen precursors and estrogen conversion, resulting in a higher breast cancer relapse rate. Therefore, active obesity management is necessary for breast cancer patients [5]. Obesity management is directly related to the survival rate of breast cancer patients, and is very important for balancing their energy intake and consumption [6]. Energy intake is mostly done through eating, and the obtained energy is consumed through basic metabolism, exercise, and the thermal effect of food [7]. In obesity management, it is important to increase the protein content and decrease the fat content of one's diet, which is effective in reducing body fat loss and maintaining the body weight [8]. Basic metabolism is responsible for $60-70 \%$ of the total energy consumption, followed by physical activities, including exercise (15-30\%) and the thermal effect of food intake (10\%) [9]. Basic metabolism plays a major role in controlling the body weight. Aerobic exercises are effective in directly burning body fat, and are conducted to increase the basal metabolic rate. Anaerobic exercises, on the other hand, are effective in increasing the energy consumption by augmenting the muscles and bones [10]. The thermal effect of food is triggered by ingesting foods containing a substance that induces heat generation. For example, capsaicin, responsible for the spicy taste of pepper, is known to promote energy consumption by activating the brown adipose tissue in the body. Moreover, catechin and caffeine, which are abundant in green tea, act on the sympathetic nerves and promote the secretion of norepinephrine to activate the beta-sympathetic nerve receptors and induce energy consumption [11]. Consequently, the obesity management of breast cancer patients should consider both the energy intake and energy consumption. Especially, it is necessary to find ways to increase the patients' basal metabolic rate and exercise as well as the thermal effect of foods at the same time evaluated the obesity-related lifestyle associated with the obesity of breast cancer patients and reported that these patients tended to have obesity-related nutritional intake and exercise patterns [12]. 
Lee, Park, Kim and Kang examined the effects of nutritional interventions on breast cancer patients, focusing on clinical nutritionists, and showed that nutritional interventions decreased the frequency of taking alcohol and health supplements in these patients [13]. Moreover, previous studies have revealed that a variety of aerobic and anaerobic exercise programs are effective in weight management [8-10] and that dietary control therapies such as a protein-supplemented modified diet were effective as well $[6,11,12]$. These previous studies, however, were conducted without controlling the diverse factors associated with the obesity of breast cancer patients. Moreover, they could not approach the energy intake and consumption from diverse angles, which was another of their limitations. Thus, to establish the factors related to breast cancer patients' obesity, it is necessary to control such factors to the extent possible.

This study aimed to identify the factors associated with the obesity of breast cancer patients by applying the propensity score matching (PSM) method to make up for the limitations of the previous studies. PSM is a technique that can control the co-variables of the treatment and control groups, other than the target variables, by randomizing the samples and creating a situation similar to a clinical test. Most observational studies have used non-randomized sampling methods, but these methods cannot control the selection bias. As such, there may be errors in the inferences regarding the causal relationships of the variables, or under- or overestimated results. Therefore, it is necessary to select the variables that can control the disruption variables in the experimental design stage, and then to calculate the controlled disruption variables as certain covariates, which can be used to make the treatment and control groups similar to each other [14]. In this respect, PSM can more precisely identify the causal relationship between factors by randomly assigning data and creating a situation similar to a clinical trial. The objectives of this study were to identify the factors affecting the obesity of breast cancer patients and to provide basic data for the development of an effective obesity management program for them using PSM and data from the Korea National Health and Nutrition Examination Survey (KNHANES) with a bigger sample size and a higher level of representativeness.

\section{Materials and Methods}

As mentioned above, this study was a cross-sectional correlation study that aimed to identify the factors affecting the obesity of breast cancer patients and to provide basic data for the development of an effective obesity management program for them.

For this study, 231 breast cancer patients who had been diagnosed with breast cancer and had been treated for more than 3 months prior to this study among the adult participants (aged 19 and older) of the $5^{\text {th }}$ KNHANES first year (2010), second year (2011), and third year (2012), $6^{\text {th }}$ KNHANES first year (2013), second year (2014), and third year (2015), and $7^{\text {th }}$ KNHANES first year (2016) examinations and health surveys were selected. There were 8,473 participants $(77.5 \%$ participation rate) in $5^{\text {th }}$ KNHANES first year (2010), 8,055 (76.1\% participation rate) in $5^{\text {th }}$ KNHANES second year (2011), and 7,645 (75.9\% participation rate) in $5^{\text {th }}$ KNHANES third year (2012), and 41, 36, and 29 of them, respectively, were breast cancer patients. There were 7,580 participants (75.0\% participation rate) in $6^{\text {th }}$ KNHANES first year $(2013)$ 7,550 (73.9\% participation rate) in $6^{\text {th }}$ KNHANES second year (2014), and 7,380 (73.4\% participation rate) in $6^{\text {th }}$ KNHANES third year (2015), and 22, 28, and 37 of them, respectively, were breast cancer patients. Finally, there were 8,150 participants $\left(75.4 \%\right.$ participation rate) in $7^{\text {th }}$ KNHANES first year (2016), and 38 of them were breast cancer patients. For this study, raw data from the KNHANES homepage operated by Korea centers for Disease Control and Prevention (KCDC) were downloaded and used by each subject after signing the statistical data user compliance statement and security pledge. The raw data open to the public do not have personal identification data. KNHANES has been conducted to identify the national health and nutritional status based on Article 16 of the National Health Promotion Act of the Republic of Korea. The provided statistics were government-designated statistics (Approval No. 117002) based on Article 17 of the Statistics Act. This study was conducted upon the approval of the Ethics Review Committee of KCDC. KNHANES produces the statistics required for selecting the health-vulnerable group and for evaluating if the health policies and projects are effectively delivered by identifying the public health and nutritional status and trend. It provides the statistics related to smoking, drinking, physical activities, and obesity requested by the World Health Organization (WHO) and the Organization for Economic Co-operation and Development (OECD). KNHANES samples 23 households per district from a total of 192 districts every year, and selects approximately 10,000 people aged 1 year or older to participate in the survey. It has released raw data up to the $7^{\text {th }}$ survey first year (2016). It was conducted as a short-term survey system (2-3 months) for every 3 years from the $1^{\text {st }}$ survey $(1998)$ to the $3^{\text {rd }}$ survey (2005). It has been an annual survey system, however, from the $4^{\text {th }}$ survey (2007-2009), using the rolling sampling survey method. Therefore, the 3 years are circular samples independent of one another. The sampling framework of KNHANES is based on the most recent Population and Housing Census at the time of the sampling design. It aimed to collect data from the most representative sample of the South Korean citizens ( $\geq 1$ year) living in the country (the target population). The $5^{\text {th }}$ survey (2010-2012), however, used the registered resident population and condominium complex price survey data because the Population and Housing Census data at the time of sampling were too old. A two-step stratified cluster sampling method was used, which treated a district and a household as the $1^{\text {st }}$ and $2^{\text {nd }}$ sampling units, respectively. The $7^{\text {th }}$ survey first year stratified the sample based on city, province, district or township, and housing type (single house, condominium, and new condominium), and used the living space ratio as an internal stratification standard. Nursing homes, military facilities, prisons, and foreigners were excluded from the sampling. 


\section{matching}

In this study, the collected data were analyzed using SPSS 21.0 (SPSS Korea Data Solution Inc.) as follows. PSM was used to minimize the errors in the causal relationships caused by the subject selection bias. PSM calculates the disruption variables as covariates, and makes the treatment and control groups similar to each other to control the disruption variables related to the dependent variables. Logistic regression was used as the propensity score estimation algorithm. 1:1 matching was done using nearest-neighbour matching as the matching algorithm. Moreover, the individuals outside the common observation area were excluded to improve the data balance. The categorical variables were analyzed using the $\chi^{2}$ test to examine the equivalence of the covariates between the two groups before and after matching. The covariates associated with obesity are socioeconomic factors (e.g., age, household income level, education level, and marital status) and healthstatus-related factors (e.g., doctor-diagnosed diseases, activity restrictions, depression, stress perception, and menopause). The factors related to lifestyle included smoking, drinking, nutrition label awareness, and nutrition label usage. Another factor was subjective figure recognition.

Fifty-five breast cancer patients were classified as obese before matching, but there were only 54 breast cancer patients who were obese after matching. There were 108 breast cancer patients in all in the analysis after evenly distributing the nonobese breast cancer patients. The study was conducted after being approved by the Institutional Bioethics Review Committee (SYMC IRB: 18-14). After controlling the covariates associated with obesity, logistic regression analysis was performed to identify the factors associated with the obesity of breast cancer patients. The odds ratio (OR) and 95\% confidence interval $(95 \%$ CI $)$ were calculated. Statistical difference was determined at $\mathrm{p}<0.05$, unless stated otherwise. In this study, items suitable for the study objectives were selected among the physical examination and health items in the $5^{\text {th }}-7^{\text {th }}$ KNHANES. The selected items were included in the questionnaires of the $5^{\text {th }}-7^{\text {th }}$ KNHANES.

This study defined the breast cancer patients as those who responded "Yes" to the question "Have you been diagnosed with breast cancer by a doctor?" The time elapsed after the diagnosis was calculated by subtracting the age at diagnosis from the current age.

The BMI was calculated using the obesity prevalence variable generated by the KNHANES research team and the height and weight information provided by the respondents. It was calculated by dividing the body weight $(\mathrm{kg})$ by the square of height (m). Obesity was defined as a BMI of $25 \mathrm{~kg} / \mathrm{m}^{2}$ or more. In KNHANES, the height and weight are measured by trained examiners. The height is measured in $0.1 \mathrm{~cm}$ increments, using a mobile stadiometer (Holtain Ltd., Crymych, United Kingdom), and the body weight is measured using a scale (Giant 150N; HANA Co. Ltd., Seoul, South Korea), with the participant wearing a light gown or an undergarment, in $0.1 \mathrm{~kg}$ increments.

Weight control methods, the degree of physical activity, nutrient intake, the basal metabolic rate, and the thermal effect of food were considered obesity-related factors in this study. The weight control methods were identified based on the participants" response to the question "Please indicate what method you used to reduce or maintain body weight over the past year." When a responder marked an answer, it was considered "Yes". The degree of physical activity included the number of times one walks per week ("How many days did you walk for at least 10 minutes in the past week?"), the duration of walking for 1 week, and the number of days of doing strength exercise per week ("How many days did you do strength exercise such as push-up, sit-up, weight lifting, and use of a dumbbell or a chin-up bar in the past week?"). The total energy intake per day was calculated by multiplying the amount of food consumed and the unit energy using a 24-hour recall method. For protein, fat, and carbohydrates, the total daily intake and the energy ratio of each nutrient from the total energy intake were calculated at the same time. For sodium, the nutrient density was calculated by dividing the sodium intake by the total energy intake. The basal metabolic rate was calculated using the Mifflin-St. Jeor method. The thermal effect of food was calculated by multiplying the daily total energy intake by $0.1[15]$.

Age, among the socioeconomic factors, was classified into below 50, 51-59, 60-69, and 70 years old. Household income was classified into low, middle-low, middle-high, and high based on the household equivalence income, which was estimated from the responses to the open household income question and the number of household members (monthly mean household income/square root of the number of households). Education level was classified into below elementary school, middle school graduate, high school graduate, and college graduate. Marital status was divided into married and single. The factors related to health status included doctor-diagnosed hypertension, dyslipidemia, stroke, diabetes, and arthritis. The activity restraints were determined by the response (Yes/No) to the question "Do you have any restraints in daily life or social activities due to a health issue, a physical disability, or a mental disability?" Depression was categorized as "yes" or "no" according to the response to the question "Did you ever feel so sad or desperate in the past year that it affected your daily life for more than two consecutive weeks?" Stress awareness was determined by the response to the question "How much stress do you experience in your daily life?" "Experience very much stress" and "Experience much stress" were classified as "Experience stress much," and "Experience a little stress" and "Experience little stress" were classified as "Experience little stress." When a respondent answered "Menopause" to the question "Do you still have menstruation?" or "Yes" to the question "Are you currently menopausal?" she was classified as menopausal. All the other respondents were classified as non-menopausal. "Smoking" was determined based on the respondents' response to the question "Do you smoke now?" When the response was "Smoke daily" or "Smoke occasionally," the respondent was classified as a smoker. When the response was "Used to smoke but no longer do" or "Never smoked," the respondent was classified as a non-smoker. "Drinking" was determined based 
on the response to the question "How often did you drink in the past year?" When the response was "Never drank in the past year," the respondent was classified as a non-drinker. When the response was "Less than once a month" or "More than 4 times per week," the respondent was classified as a drinker. The nutrition label awareness was classified as "Yes" or "No" according to the response to the question "Do you know that there are "nutrition labels'?" The nutrition label usage was determined by the response (Yes/No) to the question "Do you read the nutrition label when purchasing or choosing a processed food item?" Subjective figure recognition was determined according to the response (Normal or Underweight/ Overweight) to the question "What do you think about your current body figure?"

\section{Results}

The general characteristics of the subjects prior to PSM are shown in Table 1. Of the total of 218 subjects in this study, 55 $(25.2 \%)$ were obese and $163(74.8 \%)$ were not. Most of the obese breast cancer patients were in the 60s (17 subjects; $30.9 \%$ ), followed by those in the 70 s (15 subjects; $27.3 \%)$, 50s (13 subjects; $23.6 \%$ ), and those who were below 50 (10 subjects; $18.2 \%)$. As for the household income level, middlelow was the most common (16 subjects; 29.1\%). The highest level of education was elementary school graduate (26 subjects; $47.3 \%)$, and 49 subjects $(89.1 \%)$ were married. The doctor-diagnosed diseases were arthritis (35 subjects; 63.6\%), diabetes (33 subjects; 60.0\%), hypertension (28 subjects; $50.9 \%$ ), dyslipidemia (25 subjects; $45.5 \%)$, and stroke ( 8 subjects; $14.5 \%)$. It was found that 33 subjects $(60.0 \%)$ were menopausal, $16(29.1 \%)$ had high stress perception, $15(27.3 \%)$ had depression, and $13(23.6 \%)$ had activity restraints. One subject $(1.8 \%)$ was a smoker, $11(20.0 \%)$ were drinkers, 31 $(56.4 \%)$ were aware of nutrition labels in their daily lives, and $15(27.3 \%)$ used nutrition labels (\%). Forty-four subjects $(80.0 \%)$ were recognized as overweight.

The obesity-related characteristics of the study subjects were analyzed using $\chi^{2}$ test before and after conducting PSM to confirm that PSM was done well (Tables 1 and 2). The results showed that of the 218 study subjects, 55 were obese, but it became 54 after PSM. Prior to PSM, the two groups were significantly different in terms of whether they had hypertension, dyslipidemia, diabetes, arthritis, and depression, and in terms of nutrition label awareness, nutrition label use, and subjective figure recognition (Table 1). After PSM, the two groups were significantly different in terms of whether they had hypertension and diabetes, and in terms of subjective figure recognition (Table 2).

Logistic regression was conducted to evaluate the factors affecting the obesity of breast cancer patients based on the PSM results (Table 3). The study subjects who exercised to control their weight had a 0.62 -fold lower probability of becoming obese than those who did not exercise. The subjects who ate less food had a 0.57 -fold lower probability of becoming obese than those who did not reduce the amount of their food intake. The subjects who did strength exercise for more days, who had a higher protein intake, and who had a higher thermal effect of food had 1.51(1/0.66)-, 1.26(1/0.79)-, and 1.03(1/0.97)-fold higher probabilities, respectively, of becoming non-obese.

Table 1. Characteristics of breast cancer survivors before propensity score matching $(N=218)$.

\begin{tabular}{|c|c|c|c|c|c|}
\hline Variables & & Non-obese $(n=163)$ & Obese $(n=55)$ & $x^{2}$ & $\mathbf{p}$ \\
\hline \multirow{4}{*}{ Age (year) } & $<50$ & $38(17.4)$ & $10(4.6)$ & \multirow{4}{*}{2.42} & \multirow{4}{*}{0.489} \\
\hline & $51-59$ & $49(22.5)$ & $13(6.0)$ & & \\
\hline & $60-69$ & $44(20.2)$ & $17(7.8)$ & & \\
\hline & $>70$ & $32(14.7)$ & $15(6.9)$ & & \\
\hline \multirow{4}{*}{ Family income } & Low & $33(15.1)$ & $13(6.0)$ & \multirow{4}{*}{1.49} & \multirow{4}{*}{0.683} \\
\hline & Middle-low & $38(17.4)$ & $16(7.3)$ & & \\
\hline & Middle-high & $43(19.7)$ & $13(6.0)$ & & \\
\hline & High & $49(22.5)$ & $13(6.0)$ & & \\
\hline \multirow{4}{*}{ Education } & Elementary or less & $55(25.2)$ & $26(11.9)$ & \multirow{4}{*}{4.71} & \multirow{4}{*}{0.194} \\
\hline & Middle school & $21(9.6)$ & $7(3.2)$ & & \\
\hline & High school & $43(19.7)$ & $14(6.4)$ & & \\
\hline & Over college & $44(20.2)$ & $8(3.7)$ & & \\
\hline \multirow{2}{*}{ Marital status } & Married & $150(68.8)$ & 49 (22.5) & \multirow{2}{*}{1.83} & \multirow{2}{*}{0.175} \\
\hline & Single & $13(6.0)$ & $6(2.8)$ & & \\
\hline
\end{tabular}


Factors affecting the obesity of the South Korean breast cancer patients as determined using propensity score matching

\begin{tabular}{|c|c|c|c|c|c|}
\hline \multirow{2}{*}{ Hypertension } & Yes & $52(23.9)$ & $28(12.8)$ & \multirow{2}{*}{6.39} & \multirow{2}{*}{0.011} \\
\hline & None & $111(50.9)$ & $27(12.4)$ & & \\
\hline \multirow{2}{*}{ Dyslipidemia } & Yes & $50(22.9)$ & $25(11.5)$ & \multirow{2}{*}{1.24} & \multirow{2}{*}{0.017} \\
\hline & none & $113(51.8)$ & $30(13.8)$ & & \\
\hline \multirow{2}{*}{ Stroke } & Yes & $17(7.8)$ & $8(3.7)$ & \multirow{2}{*}{0.68} & \multirow{2}{*}{0.407} \\
\hline & None & $146(67.0)$ & $47(21.6)$ & & \\
\hline \multirow{2}{*}{ Diabetes mellitus } & Yes & $11(5.0)$ & $33(15.1)$ & \multirow{2}{*}{72.38} & \multirow{2}{*}{$<0.001$} \\
\hline & None & $152(69.7)$ & $22(10.1)$ & & \\
\hline \multirow{2}{*}{ Arthritis } & Yes & $63(28.9)$ & 35 (16.1) & \multirow{2}{*}{2.56} & \multirow{2}{*}{0.009} \\
\hline & None & $100(45.9)$ & $20(9.2)$ & & \\
\hline \multirow{2}{*}{ Limitation of activity } & Yes & $32(14.7)$ & $13(6.0)$ & \multirow{2}{*}{0.4} & \multirow{2}{*}{0.324} \\
\hline & None & $131(60.1)$ & $42(19.3)$ & & \\
\hline \multirow{2}{*}{ Depression } & Yes & $30(13.8)$ & $15(6.9)$ & \multirow{2}{*}{2.64} & \multirow{2}{*}{0.044} \\
\hline & None & $133(61.0)$ & $40(18.3)$ & & \\
\hline \multirow{2}{*}{ Stress cognition } & High & 38 (17.4) & $16(7.3)$ & \multirow{2}{*}{0.73} & \multirow{2}{*}{0.391} \\
\hline & Low & $125(57.3)$ & $39(17.9)$ & & \\
\hline \multirow{2}{*}{ Menopausal status } & Yes & 75 (34.4) & $22(10.1)$ & \multirow{2}{*}{0.6} & \multirow{2}{*}{0.269} \\
\hline & none & $88(40.4)$ & $33(15.1)$ & & \\
\hline \multirow{2}{*}{ Smoking† } & Smoker & $7(3.2)$ & $1(0.5)$ & \multirow{2}{*}{0.71} & \multirow{2}{*}{0.357} \\
\hline & Non-smoker & $156(71.6)$ & $54(24.8)$ & & \\
\hline \multirow{2}{*}{ Drinking } & Yes & $44(20.2)$ & $11(5.0)$ & \multirow{2}{*}{1.06} & \\
\hline & None & $119(54.6)$ & $44(20.2)$ & & 0.302 \\
\hline & Yes & $114(52.3)$ & $31(14.2)$ & & \\
\hline Cognition of nutrition labeling & None & 49 (22.5) & $24(11.0)$ & 3.4 & 0.048 \\
\hline & Yes & $98(45.0)$ & $15(6.9)$ & & \\
\hline Using of nutrition labeling & None & $65(29.8)$ & $40(18.3)$ & 2.81 & 0.003 \\
\hline & Under or normal weight & $126(57.8)$ & $11(5.0)$ & & \\
\hline Perception about body ımage & Over weight & $37(17.0)$ & $44(20.2)$ & 68.91 & $<0.001$ \\
\hline
\end{tabular}

Table 2. Characteristics of Breast Cancer Survivors after Propensity Score Matching (N=108).

\begin{tabular}{|c|c|c|c|c|c|}
\hline Variables & & Non-obese $(n=54)$ & Obese $(n=54)$ & $x^{2}$ & $\mathbf{p}$ \\
\hline \multirow{4}{*}{ Age (year) } & $<50$ & $14(13.0)$ & $10(9.3)$ & \multirow{4}{*}{4.11} & \multirow{4}{*}{0.25} \\
\hline & $51-59$ & $17(15.7)$ & $13(12.0)$ & & \\
\hline & $60-69$ & $16(14.8)$ & $16(14.8)$ & & \\
\hline & $>70$ & $7(6.5)$ & 15 (13.9) & & \\
\hline \multirow{3}{*}{ Family income } & Low & $9(8.3)$ & $13(12.0)$ & \multirow{3}{*}{1.5} & \multirow{3}{*}{0.681} \\
\hline & Middle-low & $14(13.0)$ & $16(14.8)$ & & \\
\hline & Middle-high & 15 (13.9) & $12(11.1)$ & & \\
\hline
\end{tabular}




\begin{tabular}{|c|c|c|c|c|c|}
\hline & \\
\hline & High & $16(14.8)$ & $13(12.0)$ & \multirow{5}{*}{6.51} & \multirow{5}{*}{0.089} \\
\hline \multirow{4}{*}{ Education } & Elementary or less & $17(15.7)$ & $26(24.1)$ & & \\
\hline & Middle school & $6(5.6)$ & $7(6.5)$ & & \\
\hline & High school & $16(14.8)$ & $14(13.0)$ & & \\
\hline & Over college & $15(13.9)$ & $7(6.5)$ & & \\
\hline \multirow{2}{*}{ Marital status } & Married & $48(44.4)$ & $48(44.4)$ & \multirow{2}{*}{0.71} & \multirow{2}{*}{0.339} \\
\hline & Single & $6(5.6)$ & $6(5.6)$ & & \\
\hline \multirow{2}{*}{ Hypertension } & Yes & $17(15.7)$ & $28(25.9)$ & \multirow{2}{*}{3.81} & \multirow{2}{*}{0.051} \\
\hline & None & $37(34.3)$ & $26(24.1)$ & & \\
\hline \multirow{2}{*}{ Dyslipidemia } & Yes & $19(17.6)$ & $24(22.2)$ & \multirow{2}{*}{0.16} & \multirow{2}{*}{0.69} \\
\hline & none & $35(32.4)$ & $30(27.8)$ & & \\
\hline \multirow{2}{*}{ Stroke } & Yes & $6(5.6)$ & $8(7.4)$ & \multirow{2}{*}{0.78} & \multirow{2}{*}{0.375} \\
\hline & None & $48(44.4)$ & $46(42.6)$ & & \\
\hline \multirow{2}{*}{ Diabetes mellitus } & Yes & $6(5.6)$ & $33(30.6)$ & \multirow{2}{*}{34.57} & \multirow{2}{*}{$<0.001$} \\
\hline & None & $48(44.4)$ & $21(19.4)$ & & \\
\hline \multirow{2}{*}{ Arthritis } & Yes & $13(12.0)$ & $20(18.5)$ & \multirow{2}{*}{0.61} & \multirow{2}{*}{0.132} \\
\hline & None & $41(38.0)$ & $34(31.5)$ & & \\
\hline \multirow{2}{*}{ Limitation of activity } & Yes & $8(7.4)$ & $13(12.0)$ & \multirow{2}{*}{1.48} & \multirow{2}{*}{0.224} \\
\hline & None & $46(42.6)$ & $41(38.0)$ & & \\
\hline \multirow{2}{*}{ Depression } & Yes & $6(5.6)$ & $14(13.0)$ & \multirow{2}{*}{0.1} & \\
\hline & None & $48(44.4)$ & $40(37.0)$ & & 0.15 \\
\hline Otan & High & $9(8.3)$ & $16(14.8)$ & 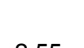 & \\
\hline & Low & $45(41.7)$ & $38(35.2)$ & 2.50 & 0.11 \\
\hline Monos ot at & Yes & $25(23.1)$ & $22(20.4)$ & 200 & 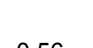 \\
\hline & none & $29(26.9)$ & $32(29.6)$ & & \\
\hline & Smoker & $2(1.9)$ & $1(0.9)$ & & \\
\hline 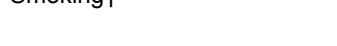 & Non-smoker & $52(48.1)$ & $53(49.1)$ & 0.04 & 0.000 \\
\hline & Yes & $14(13.0)$ & $10(9.3)$ & & 0055 \\
\hline Diniking & None & $40(37.0)$ & $44(40.7)$ & 0.05 & 0.050 \\
\hline & Yes & $36(33.3)$ & $31(28.7)$ & & \\
\hline Cognition of nutrition labeling & None & $18(16.7)$ & $23(21.3)$ & 0.98 & 0.321 \\
\hline & Yes & $19(17.6)$ & $15(13.9)$ & & \\
\hline Using of nutrition labeling & None & $35(32.4)$ & $39(36.1)$ & 0.68 & 0.407 \\
\hline & Under or normal weight & $33(30.6)$ & $11(10.2)$ & & \\
\hline 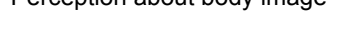 & Over weight & $21(19.4)$ & $43(39.8)$ & 21.00 & -0.001 \\
\hline
\end{tabular}

Table 3. Factors related to obesity in breast cancer survivors. 
Factors affecting the obesity of the South Korean breast cancer patients as determined using propensity score matching

\begin{tabular}{|c|c|c|c|c|c|c|c|}
\hline \multirow{4}{*}{ Age (year) } & $<50$ & Reference & - & \multirow{2}{*}{ Stress cognition } & Low & Reference & - \\
\hline & $51-59$ & 1.31 & $0.33-5.09$ & & High & 2.24 & $0.23-11.18$ \\
\hline & $60-69$ & 1.07 & $0.25-4.64$ & \multirow{2}{*}{ Menopausal status } & None & Reference & - \\
\hline & $>70$ & 3.15 & $0.63-5.64$ & & Yes & 1.18 & $0.17-7.83$ \\
\hline \multirow{4}{*}{ Family income } & Low & Reference & - & \multirow{2}{*}{ Smoking† } & Non-smoker & Reference & - \\
\hline & Middle-low & 0.65 & $0.16-2.59$ & & Smoker & 1.02 & $0.20-7.95$ \\
\hline & Middle-high & 0.59 & $0.15-2.21$ & & None & Reference & - \\
\hline & High & 0.52 & $0.12-2.22$ & Singury & Yes & 2.02 & $0.58-5.94$ \\
\hline \multirow{4}{*}{ Education } & Elementary or less & Reference & - & \multirow{2}{*}{ Cognition of nutrition labeling } & None & Reference & - \\
\hline & Middle school & 2.28 & $0.45-11.44$ & & Yes & 0.19 & $0.02-1.49$ \\
\hline & High school & 0.76 & $0.23-2.45$ & & None & Reference & - \\
\hline & Over college & 0.55 & $0.11-2.59$ & 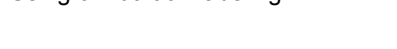 & Yes & 0.48 & $0.18-2.84$ \\
\hline \multirow{2}{*}{ Marital status } & Single & Reference & - & \multirow{2}{*}{ Perception about body image } & Under or normal weight & Reference & - \\
\hline & Married & 0.1 & $0.01-1.29$ & & Over weight & 6.03 & $2.06-10.64$ \\
\hline \multirow{2}{*}{ Hypertension } & None & Reference & - & \multirow{2}{*}{ Method of weight control (exercise) } & None & Reference & - \\
\hline & Yes & 1.17 & $0.76-4.20$ & & Yes & 0.62 & $0.51-0.95$ \\
\hline \multirow{2}{*}{ Dyslipidemia } & None & Reference & - & \multirow{2}{*}{ Method of weight control (diet) } & None & Reference & - \\
\hline & Yes & 1.16 & $0.71-1.55$ & & Yes & 0.57 & $0.38-0.99$ \\
\hline \multirow{2}{*}{ Stroke } & None & Reference & - & Walking (day/week) & & 0.38 & $0.12-1.10$ \\
\hline & Yes & 1.95 & $0.66-3.81$ & Walking (hour/day) & 0.96 & $0.93-1.01$ & \\
\hline \multirow{2}{*}{ Diabetes mellitus } & None & Reference & - & Strengthening exercise (day/week) & & 0.66 & $0.41-.80$ \\
\hline & Yes & 7.53 & $2.02-18.56$ & Total energy & 1.09 & $0.90-2.10$ & \\
\hline \multirow{2}{*}{ Arthritis } & None & Reference & - & Carbohydrate & & 1.08 & $0.97-1.21$ \\
\hline & Yes & 4.98 & $0.11-12.62$ & Protein & 0.79 & $0.65-0.97$ & \\
\hline \multirow{2}{*}{ Limitation of activity } & None & Reference & - & Fat & & 1.03 & $0.75-1,42$ \\
\hline & Yes & 1.52 & $0.52-3.98$ & Sodium density & 1.06 & $0.60-2.51$ & \\
\hline \multirow{2}{*}{ Depression } & None & Reference & - & Basal metabolic rate & & 1.01 & $0.99-1.02$ \\
\hline & Yes & 1.4 & $0.20-2.09$ & Thermal effect of food & 0.97 & $0.96-0.99$ & \\
\hline
\end{tabular}

Model fit: -2 loglikelihood $=64.32$, Cox \& Snell $R^{2}=0.54$, Nagelkerke $R^{2}=0.72, C l=$ confidence interval

\section{Discussion}

This study was conducted to evaluate the factors affecting the obesity of breast cancer patients. The discussion herein will thus mainly focus on this matter.

First, the results of this study showed that exercise significantly affected the obesity of the subject breast cancer patients. The results of this study were similar to those of the previous parallel cohort study [16] conducted in the U.S., which argued that physical activities and obesity significantly influence cancer development and death. Particularly, the results of this study showed that a subject who did strength exercise for more days per week had a lower chance of becoming obese. Physical activity is one of the effective ways of consuming energy.
Especially, it is believed that strength exercise increases the energy consumption rate of cancer patients by improving the functions related to walking, such as the walking speed, lower body strength, and balance [17]. Moreover, strength exercise increases muscle strength and endurance, and improved muscle strength enhances the performance of the basic and functional activities of daily life. Consequently, this factor increases energy consumption by enhancing the ability to conduct activities in daily life and raising the frequency of such activities [18]. Therefore, it is important to encourage breast cancer patients to engage in physical activities as a measure to prevent obesity among them. Particularly, it is necessary to develop a program that can increase their muscle strength and that can be actively used by them. In previous studies, 
however, exercise interventions for cancer patients mainly consisting of aerobic and strength exercises were often perceived as supplementary to aerobic exercise. Segal et al. examined patients with prostate cancer who were receiving radiotherapy and reported that the strength exercise group had less fatigue, better quality of life, and higher cardiorespiratory fitness and muscle strength than the non-strength-exercise group [19]. Moreover, Courneya et al. carried out an exercise intervention study on breast cancer patients and showed that the group that was receiving strength exercise and chemotherapy at the same time had a higher chemotherapy completion rate than the group that was receiving aerobic exercise and chemotherapy at the same time [20]. Consequently, it is necessary to develop various strength exercises and to apply these to breast cancer patients to prevent and manage their obesity, which is directly linked to their survival rate.

Second, the results of this study showed that reducing the amount of food intake affected the obesity of the subject breast cancer patients, and that the ratio of protein intake influenced the presence of obesity. The results revealed that it is important to control the energy intake to manage obesity. The results agreed with those of a previous study [21] on obese adults in the U.S., which reported that the obesity group consuming a high-protein diet could effectively reduce weight and maintain it. The results implied that the high-protein diet improved the subjects' satiety, increased their energy consumption, and positively affected their body composition and glucose control [22]. Additionally, protein may help in strength exercise because it builds muscles. Therefore, it will be necessary to provide systematic diet control training for managing the obesity of breast cancer patients through diet experts, and to educate breast cancer patients on the self-management diet method that can increase their protein intake.

Third, the results of this study confirmed that breast cancer patients with a higher thermal effect of food have less chances of becoming obese. The results of this study are similar to those of the study by Lee [15], which examined the ecological system of youth obesity in South Korea and emphasized that energy consumption was linked to the basal metabolic rate, physical activities, and the thermal effect of food. The thermal effect of food is caused by ingesting foods containing a substance inducing heat generation. For example, capsaicin, which is responsible for the spicy taste of red pepper, promotes energy consumption by activating the brown adipose tissue in the body. Moreover, catechin and caffeine, which are abundant in green tea, act on the sympathetic nerves to promote the secretion of norepinephrine, which induces energy consumption by activating the beta-sympathetic receptors [11]. It will be necessary, however, to systematically conduct additional studies associated with the thermal effect of food because the previous studies failed to sufficiently evaluate such. It will be possible to more effectively manage the obesity of breast cancer patients if measures will be implemented to increase the thermal effect of food in addition to controlling the quantity of their food intake and increasing their protein intake.

\section{Conclusion}

The objectives of this study were to confirm the factors affecting the obesity of breast cancer patients and to provide baseline data for the development of an effective obesity management program for them. Towards this end, this study utilized data from the Korea National Health and Nutrition Examination Survey (KNHANES) and propensity score matching (PSM). The results of this study showed that the degree of physical activity, the number of days of doing strength exercise, food intake reduction, the protein intake ratio, and the thermal effect of food affected the obesity of the subject breast cancer patients. This study used PSM to control the factors potentially influencing the obesity of the subjects to the extent possible. It had a limitation, however, in that it had to use only the variables used in KNHANES. Therefore, future studies are needed to examine the factors associated with the obesity management of breast cancer patients in various aspects, using a wide range of data, and to suggest political measures for managing the obesity of breast cancer patients.

\section{Conflicts of Interest}

No competing financial interests exist.

\section{References}

1. Jung KW, Won YJ, Kong HJ, Oh CM, Lee DH, Lee JS. Cancer Statistics in Korea: incidence, mortality, survival, and prevalence in 2011. Cancer Res Treat 2014; 46:109-123.

2. Korean Statistics Information Service 2018.

3. Kim Z, Min SY, Yoon CS, Lee HJ, Lee JS, Youn HJ, Park HK, Noh DY, Hur MH, Korean Breast Cancer Society. The basic facts of Korean breast cancer in 2011: results of a nationwide survey and breast cancer registry database. J Breast Cancer 2014; 17:99-106.

4. Lin NU, Vanderplas A, Hughes ME, Theriault RL, Edge SB, Wong YN, Blayney DW, Niland JC, Winer EP, Weeks JC. Clinicopathologic features, patterns of recurrence, and survival among women with triple negative breast cancer in the National Comprehensive Cancer Network. Cancer 2012; 118:5463-5472.

5. Protani M, Coory M, Martin JH. Effect of obesity on survival of women with breast cancer: systematic review and meta-analysis. Breast Cancer Res Treat 2010; 123:627-635.

6. Kang SY. Hormone Therapy for Metastatic Breast Cancer. Korean J Med 2017; 92:251-258.

7. Beral V, Million Women Study Collaborators. Breast cancer and hormone-replacement therapy in the million women study. Lancet 2013; 362:419-427.

8. Pfeiler G, Königsberg R, Fesl C, Mlineritsch B, Stoeger H, Singer CF, Pöstlberger S, Steger GG, Seifert M, Dubsky P, Taucher S, Samonigg H, Bjelic-Radisic V, Greil R, Marth C, Gnant M. Impact of body mass index on the efficacy of endocrine therapy in premenopausal 
matching

patients with breast cancer: an analysis of the prospective ABCSG-12 trial. J Clin Oncol 2013; 29:2653-2659.

9. Ewertz M, Jensen MB, Gunnarsdóttir KÁ, Højis I, Jakobsen EH, Nielsen D, Stenbygaard LE, Tange UB, Cold S. Effect of obesity on prognosis after early-stage breast cancer. J Clin Oncol 2010; 29:25-31.

10. Chan DS, Vieira AR, Aune D, Bandera EV, Greenwood DC, McTiernan A, Navarro Rosenblatt D, Thune I, Vieira R, Norat T. Body mass index and survival in women with breast cancer-systematic literature review and metaanalysis of 82 follow-up studies. Ann Oncol 2014; 25:1901-1914

11. Jang EJ, Kim DG, Kim JM, Seo HJ, Oh SH. Weight reduction effect of extract of fermented red pepper on female college students. J Korean Soc Food Sci Nutr $2003 ; 32: 479-484$.

12. Seo JS, Park HA, Kang JH, Kim KW, Jo YG, Her YI, Park YR. Obesity and obesity-related lifestyles of Korean breast cancer survivors. Korean J Health Promot 2014; 14:93-102.

13. Lee KM, Park JS, Kim HM, Kang SA. Nutritional intervention for dietary behavior modification in breast cancer patients. J Korea Acad Industr Coop Soc 2018; 19:444-450.

14. Austin PC. A critical appraisal of propensity-score matching in the medical literature between 1996 and 2003. Stat Med 2008; 27:2037-2049.

15. Lee HN. Development and evaluation of system dynamics model with ABM for early adult obesity: focused cognition-behavior model. Doctoral dissertation Kyung Hee University, Korea 2016.

16. Maliniak ML, Patel AV, McCullough ML, Campbell PT, Leach CR, Gapstur SM, Gaudet MM. Obesity, physical activity, and breast cancer survival among older breast cancer survivors in the Cancer Prevention Study-II Nutrition Cohort. Breast Cancer Res Treat 2018; 167:133-145.
17. Galvao DA, Nosaka K, Taaffe DR, Spry N, Kristjanson LJ, McGuigan MR, Suzuki K, Yamaya K, Newton RU. Resistance training and reduction of treatment side effects in prostate cancer patients. Med Sci Sports Exerc 2006; 38:2045-2052.

18. Litterini AJ, Fieler VK, Cavanaugh JT, Lee JQ. Differential effects of cardiovascular and resistance exercise on functional mobility in individuals with advanced cancer: a randomized trial. Arch Phys Med Rehabil 2013; 94:2329-2335.

19. Segal RJ, Reid RD, Courneya KS, Sigal RJ, Kenny GP, Prud'Homme DG, Malone SC, Wells GA, Scott CG, D'Angelo MES. Randomized controlled trial of resistance or aerobic exercise in men receiving radiation therapy for prostate cancer. J Clin Oncol 2009; 27:344-351.

20. Courneya KS, Segal RJ, Mackey JR, Gelmon K, Reid RD, Friedenreich CM, Ladha AB, Proulx C, Vallance JKH, Lane K, Yasui Y, McKenzie DC. Effects of aerobic and resistance exercise in breast cancer patients receiving adjuvant chemotherapy: a multicenter randomized controlled trial. J Clin Oncol 2007; 25:4396-4404.

21. Due A, Toubro S, Skov AR, Astrup A. Effect of normalfat diets, either medium or high in protein, on body weight in overweight subjects: a randomized 1-year trial. Int J Obes 2004; 28:1283-1290.

22. Velasquez MT, Bhathena SJ. Role of dietary soy protein in obesity. Int J Med Sci 2007; 4:72-82.

\section{*Correspondence to}

Hee Yeong Woo

Department of Nursing

Sahmyook Health University

Republic of Korea 